\title{
A feature-based concurrent engineering environment
}

\author{
N. P. Moreira, A. C. Ferreira \\ GRUCON - Mechanical Engineering Department/ \\ Universidade Federal de Santa Catarina \\ PBox. 476 - GRUCON/EMC/UFSC - 88040-900 - \\ Florianópolis/SC - Brazil \\ Tel. 55-482-319387 Fax. 55-482-341519 \\ email:npm@grucon.ufsc.bracf@grucon.ufsc.br
}

\begin{abstract}
This paper presents an approach to a Concurrent Engineering Environment (CEE) development based on Feature Technology. This proposal is specially useful in the Design for Manufacturing (DFM). In this sense, the information, related to different areas of the product life-cycle development, must have a common meaning for everyone. This may be achieved by using a constructive element called "feature" where the information is modeled. In order to support the information management some Information System requirements are defined. Some aspects of the model have been implemented in a real industrial case study.
\end{abstract}

\section{Keywords}

Concurrent engineering, product information modeling, feature technology

\section{INTRODUCTION}

Concurrent engineering is more than a new word to old concepts. It is a natural humancentered way to organize the product life-cycle development. By this way most of the usual errors and delays, during the product development are avoidable. It is a mult-effort issue where many different professionals are involved in the product implementation, each one bringing his/her own experience and needs. Design for Manufacturing (DFM) and Design for Assembly (DFA) are two of the efforts to organize the information exchange among different areas.

The GRUCON, in close cooperation with a Brazilian enterprise and the University of Amsterdam is developing a computational environment to help in the product life-cycle development. It is structured in a heterogeneous and distributed database where the 
information is modeled based on feature technology. Currently the development is concentrated in the Design for Manufacturing methodologies. In this area, a feature-based interface (developed at UFSC) for the CAD system and the information modeling are under development.

The information is represented using feature technology once the product is the link between several completely different information along the product life-cycle development. In these sense, a feature can be used as an "information key" to users from any design, manufacturing, assembly and others activities.

This paper is organized as follows: section 2 describes the concurrent engineering (CE) concepts and approaches presented in the references as well as some not well-defined aspects of the CE definition; section 3 presents a feature technology revision; section 4 describes the CEE based on an Information System; section 5 describes the CEE architecture and the feature technology role in the information modeling; section 6 presents some useful aspects of the environment in the Design for Manufacturing area; finally section 7 presents some conclusions and next steps.

\section{CONCURRENT ENGINEERING}

Concurrent Engineering for Chen et al. (1992) is a systematic approach to the concurrent design of products and their related processes in a computer integrated environment. In another point-of-view, Terpenny et al. (1992) say that CE brings to the design phase considerations related to many factors affecting total cost and performance throughout the lifecycle of a product. For Kusiak et al. (1993) CE is defined as a systematic approach to the integrated simultaneous design of products and processes, including manufacturing and support. In short, $\mathrm{CE}$ is generally recognized as a practice of incorporating various life-cycle values into the early stages of design. These values include, not only the products primary functions, but also its esthetics, manufaturability, assembly, serviceability and recyclability (Jo, 1991, Ishii, 1993).

Terpenny (1992) identified three basic components to concurrent engineering systems. These components include: improved design strategies, decision methods and supporting information and knowledge. Design strategies include general principles for design that enable or improve the function of other life-cycle processes. Decision methods described include: multifunctional teams, classical optimization methods, and artificial intelligence techniques. Supporting information and knowledge includes a discussion on geometric modeling, design by features and CIM requirements to achieve an integrated system.

In few words concurrent engineering, in the scope of this work, is a life-cycle development methodology that aims the activities integration through the information decentralization and cooperative work. This means that, every product life-cycle activity may be much better supported by concurrent engineering.

This approach primarily suggests the use of teamwork, where the team is formed by engineers and experts from all activities related to the product life-cycle (Huthwaite, 1994). One main function of the multifunctional team is to negotiate the best solution for the product development. The team is created in the earliest life-cycle phases and is responsible for all decisions made regarding the product, until the product is out of the market. Hence, teamwork involves intense collaboration and exchange of information. 
In spite of CE could be implemented without computer based support, in the industry, it is quite hard to do it once the information needs to be widely distributed. Then a computer based environment have been designed to help each activity development as well as the multifunctional team work. The CEE is designed as a heterogeneous and distributed database where each activity (an agent in this context) has its own information model and exports the relevant information to other agents (activities).

\subsection{Concurrent Engineering: doubtful aspects}

Concurrent engineering is, probably, the newest fashion in the manufacturing environment. So, it has lots of non well-defined aspects. In order to encourage the discussion some of them are briefly presented here.

\section{Design-centered approach}

Once the design is the life-cycle activity responsible for the major part of the cost definition in the product development (Bedworth, 1991), the concurrent engineering focus is in the design activity and its relationship with the remainder steps. Usually these proposals try to develop the design simultaneously with the process planning, assembly, etc.

This approach does not examine the fact that each life-cycle activity has its own problems, related with other activities. Then the same attention that has been dispensed to the design must be considered to any life-cycle activity.

\section{Concurrent or Simultaneous Engineering}

The terms concurrent engineering and simultaneous engineering are being used synonymously to refer the same methodology (Lindenberg, 1993). Specially in Brazil it is difficult to know which name is more intensely used. Generally the term is associated with its definition scope.

Analyzing the words semantics, in English or in Portuguese, is quite clear that both "concurrent" and "simultaneous" have the meaning "happen at the same time", but "concurrent" has the additional idea cooperating, agreeing Holanda (1988) and Longman (1983).

Looking at the common manufacturing process (complex parts and products), it is possible to assert that is quite uncommon to produce a part while the part has not yet been entirely designed. Besides, the $\mathrm{CE}$ concept means information exchange and cooperation in order to detect problems in advance and discuss solutions. Therefore the word "concurrent" seems to agree more with the CE main idea.

\section{Is CE a new name for CIM?}

In early 80's Computer Integrated Manufacturing (CIM) was considered the solution to any problem in an industry. During these CIM "golden" years several definitions, always increasing the scope, had been created. Unfortunately, due to the complexity of the practical aspects, no useful CIM implementations have been presented and the idea has been slowly discredited (Bedworth, 1991).

Concurrent engineering is a new name to an old idea, but not the CIM idea. CE has been used since Henry Ford and Ransom Olds automobile industries had created groups in the design phase with experts in design and production (Huthwaite, 1994). But CE is quite 
different from the CIM idea. CE can be implemented in a people-to-people approach and uses technologies (e.g., DFM-Design for Manufacturing and DFA-Design for Assembly) completely computer independent. In every case where it is possible to simplify the implementation and use non intensive computer support it should be the easiest way.

Currently CIM can be considered a computer tool to the information integration (Moreira, 1993). In this sense CIM can be a support to the information exchange in a complex Computer Engineering Environment.

\section{THE FEATURE TECHNOLOGY}

Features concept is not a unanimity in the scientific community and several works have been realized using the main idea (Shah, 1988a, b, 1991,Yeo, 1991, Hernandez, 1991, Moreira, 1992). The paper presented by Shah (1988b) shows the concept evolution. It can be very restrained like "Elements usage in generating, analyzing, or evaluating designs" - or generic "Groups of associated or related data elements." In order to aggregate the information of the whole product life-cycle development some rules had been defined about features:

- A feature must be classified in such way that seems usual for any life-cycle development area.

- There is a finite field of parts. It should be represented by a finite domain of features.

- The set of features is enough to represent a part in the domain. That is, the design process uses a features library. Once some times it is necessary to create a new feature the environment must provide support to feature specification

- The feature library is a knowledge base used by every tool (CAD, CAPP, etc.) in the environment.

A feature is an entity composite by production system's data and knowledge about itself. The main idea of this approach is the possibility to represent, under the same name, or key, all information about design, process planning, cutter path generation and so on.

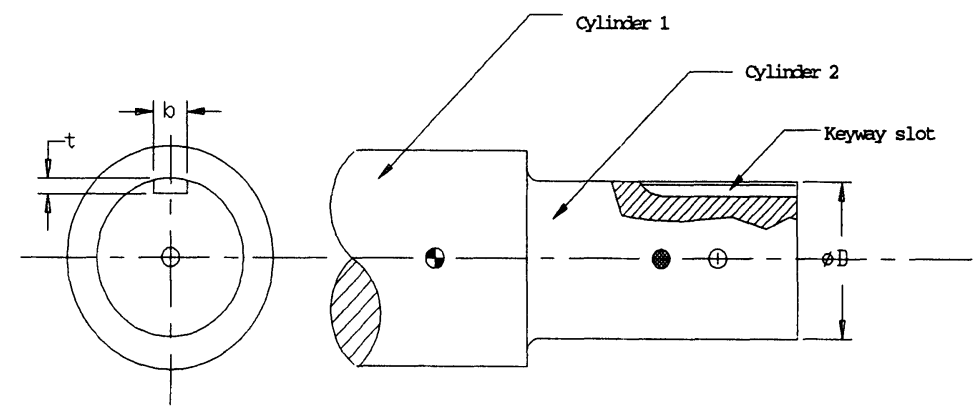

Figure $1 \mathrm{~A}$ shaft with keyway slot represented using features.

In Figure 1 there is a part that aggregate three features. The relationship among them is carried out by the reference system of each one. The features attributes are: 
- geometrical description

- finishing surface

- form tolerances

- dimensional tolerances

- surfaces

- knowledge about the manufacturing process.

The feature domain identification and classification generate feature families that are organized in hierarchies. In order to model features in such way it represents what it really means, an Object-Oriented approach (Tonshoff, 1994) is used structuring features like class and instances. This approach is described in Moreira (1992).

\section{THE INFORMATION SYSTEM SUPPORT TO CONCURRENT ENGINEERING}

In Camarinha (1994), a very interesting approach is proposed to implement concurrent engineering. In that paper a concurrent engineering environment, able to support the communication whitin engineering team, is based in the solution of three main problems: the definition of a common model, engineering information management and, process supervision.

A common model and an information management infrastructure are interrelated issues concerning the information sharing and handle. The process supervision is necessary to model the engineering process and to implement a federated loose-control process interpreter or supervisor. In a few words, it is necessary to schedule and coordinate activities during the manufacturing development. Of course this is mainly necessary in a non human-centered environment, but concurrent engineering is mainly people exchanging information, and most efforts must point to the teamwork coordination.

Following the concepts presented in sections 2 and 3 , the main requirement to the concurrent engineering implementation is the information sharing and handle. By this approach a natural framework., to support the management and sharing of information among different manufacturing phases or activities, is a network (federation) of heterogeneous and autonomous agents that are either loosely or some tightly-coupled. In this federation, an agent is involved in one activity (e.g. design) related to the product life-cycle, while several agents may take part in the same activity. On one hand production related activities are independent, (heterogeneous and autonomous) to serve different purposes. On the other hand, trivially these activities are interrelated (coupled) and need to cooperate and exchange information among themselves.

The Information System must do the following tasks:

- modeling information from different manufacturing areas;

- allow queries in any manufacturing activities;

- use the existent models;

- allow a secure information maintenance. 


\section{CEE ARCHITECTURE}

The CEE architecture is described in (Afsarmanesh, 1994). In spite of concurrent engineering could be implemented without computer support it is necessary depending on the amount of information to be processed, and its complexity.

The main requirement of the concurrent engineering approach is the availability of all the information related to any life-cycle activity, to all team members who need to access it. The information representation is heterogeneous and distributed among different autonomous agents. Depending on the automation degree some of the following tools should be used in the environment:

- CAx tools

- information servers

- analysis tools.

Currently most of product life-cycle activities have its own Computer Integrated Manufacturing tools (CAx) providing a useful aid to the development. Those tools should provide mechanisms to integrate information servers and analysis tools access. Otherwise the information servers must maintain a user interface to provide information directly to the users.

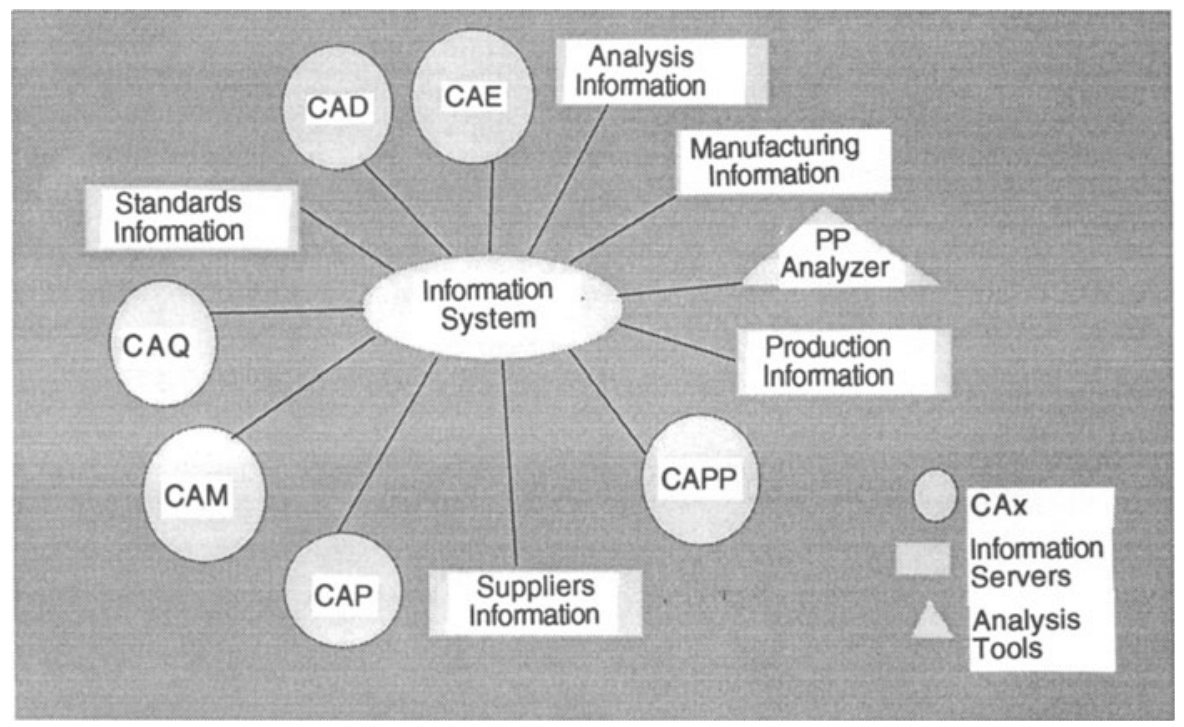

Figure 2 Information servers working together.

Each information server is related with one activity and provides answers to user questions. Each server must be modeled as an autonomous agent able to cooperate and shares information with others to solve problems. The exchange of information has to be done through an heterogeneous and distributed information system (Figure 2). By this way the requirements described in section 4 are preserved. 
For instance, if a CAD user must know if a part can be produced in-house with minimal cost, he/she can submit the design to a manufaturability analysis agent. Then, the CAPP, CAQ and CAP agents will work together to analyze the part design and to deduce the best option, in terms of the production process costs and parts/machines availability. Besides, information about third part suppliers should be analyzed to decide if it is more efficient to get the part from other manufacturers. In the example, it is possible to see the need of several agents to access the process planning and scheduling information.

The analysis tools are expert systems developed as an agent with heterogeneous database management system support. The tool intelligence degree depends on the analysis difficulty. In most cases, the user's help is necessary for a good analysis. In this case, a friendly user interface and proper communication, among the tools, must be additionally developed.

\section{CEE INFORMATION MODELING}

The information required in a concurrent engineering environment has to be analyzed specifically to each case, once it depends on the activities involved in the implementation. In Afsarmanesh et al. (1993 and 1994), a description of the information flow study, using IDEF0, in an aerospace enterprise is presented. Here it is described briefly the product model.

During the product life-cycle many different kinds of information are handled by each activity, using its own representation approach and storage strategies. Marketing, design, manufacturing and assembly phases develop activities where the product information is defined and used to generate the final product. During this process, several other pieces of information are defined and aggregated to the product definition, so that it can be used as an integration element in a concurrent engineering environment. Then, it is possible to say that the product definition is the main concept to which other manufacturing information is related.

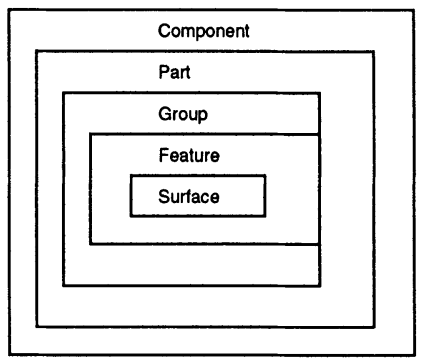

Figure 3 Product model hierarchy.

As described in Afsarmanesh et al. (1994), the product is defined hierarchically (Figure 3). The component level is user defined and can be reused in other product definitions. In this hierarchic definition, the component complexity is simplified in its sub-components definitions, while the functionality and characteristics of sub-components are more detailed. A simple component is described by one or more parts. A part is defined as a non-assembled element produced by one piece of raw material. Parts constitute the last level that can be defined by the user. One part can be composed of as many different preexistent groups and features as necessary to represent its functionality. Groups are composed of features and generally 
describe a standard constructive element. Both groups and features are available in libraries. Each library supports the manufacturing needs of one specific product domain.

The features are the principal element in the product representation (Moreira, 1991, 1992, 1993, Afsarmanesh, 1993, 1994 and Tonshoff, 1994). By those constructive components it is possible to link information from different product-life-cycle activities maintaining the link among them. This is possible because the features provide a functional representation valid for every activity. Each feature represents a design function used by the designer in the product conception phase. With this constructive element the part is built in a function assembly process. One feature can be generic defining a shape and its dimensions. A Form Feature can be used for many different purposes. In this basic feature a function can be aggregated, in order to represent more information. This new feature is called Functional Feature. Surface finishing and tolerances, machining process and thermochemical process are examples of such functions. In Figure 4 there are many features put together to build a part. Some of them, like the two cylinders and the hole, are just shapes where some other features are overlapped. The retention ring groove, for example is a shape with function. About the cylinder it is possible to say just dimensions, but concerning a specific retention ring groove it is possible to say tolerances, finishing surface, dimension range as well as, the machining process.

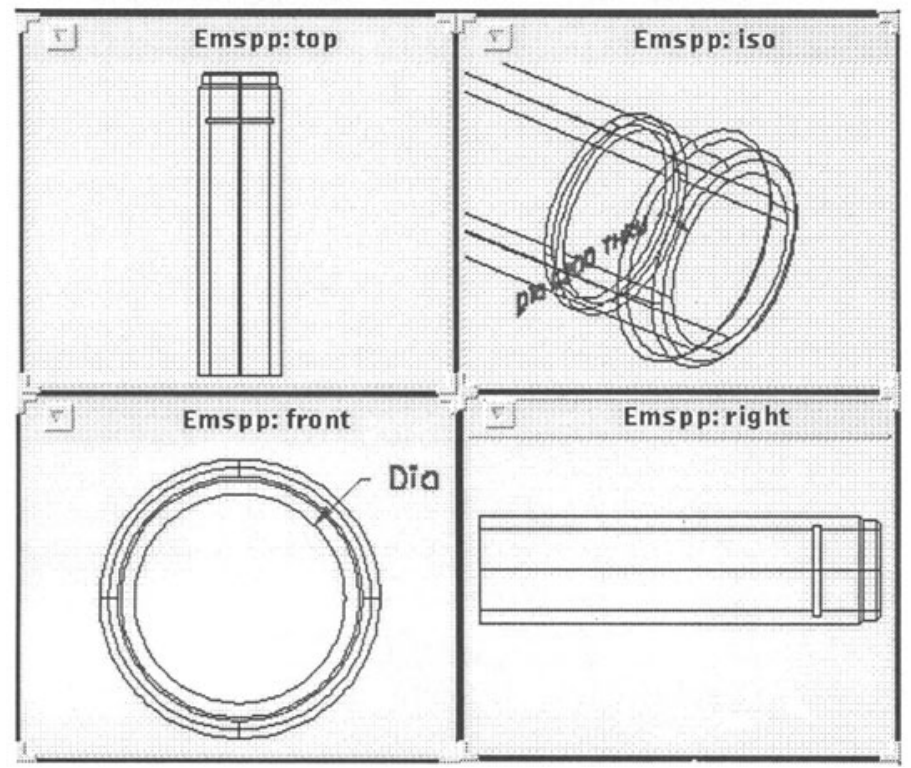

Figure 4 Feature-based product representation.

The product model is the important unifying piece of information among different activities within the Concurrent Engineering environment. As described in earlier section, it is represented hierarchically. Features are structured in subtypes that represents a specific part domain, for instance, rotational parts, prismatic parts, sheets, etc. As described earlier a feature should aggregate generic information (form-features) and information about functionality what 
can improve its representation. In the model presented in Figure 5 it is represented by a multiple inheritance between FORM_FEATTURE and FUNCTIONAL_FEATURE. The type RETENTION_GROOVE is a functional feature derived from a generic feature GROOVE and is described by additional attributes. In the example of the Figure 5 just rotational features are represented like a subtype of form_features, but any other kind of feature should be represented by the same way.

The methodology used to implement a Concurrent Engineering Environment consist, basically, of determining part families based on the geometry of the part and its features. A company may already have their parts classified into families. However, the families already existent in a company may not be appropriate for a manufacturing database based on features. Therefore, it is advised that a thorough study on all products of the company should be carried out, even if the company already has parts grouped into families.

In a company being studied, products such as valves and landing gears are produced (Moreira, 1994). In this case it was decided to focus attention on the hydraulic equipment such as valves and actuators. These products have:

- similar functions;

- similar geometric complexity;

- the same manufacturing technology;

- manufacturing planning for the following 12 months, i.e., these products are on order for delivery during the following 12 months;

- a higher frequency of new designs compared to other products.

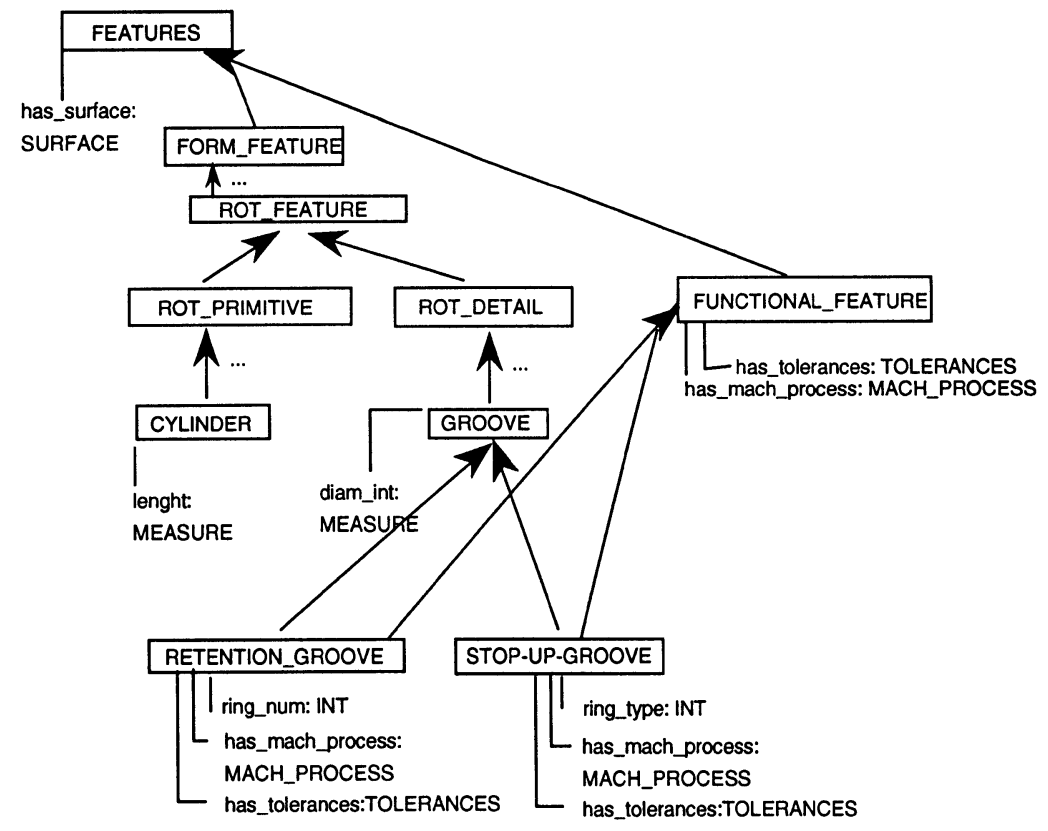

Figure 5 Feature model. 
Among the hydraulic equipment, it was decided to gather information on the rotational parts belonging to these products. Attention was given to the following groups of parts (see Figure 6):

- shafts with constant diameter, without holes or with stepped holes;

- stepped shafts, without holes or with holes having constant diameter.

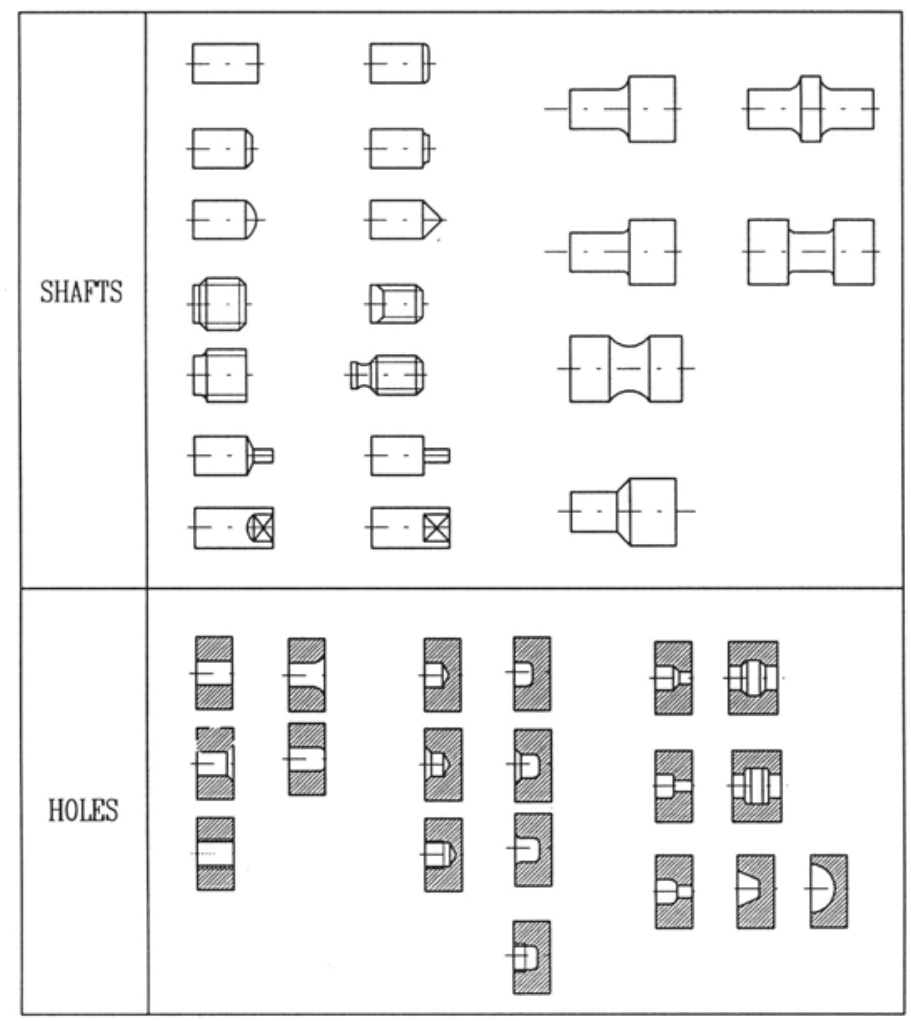

Figure 6 Features found in rotational parts.

\section{CONCLUSIONS}

In the old times the craftsman was, certainly, the first person to use the concept of CE, because the whole life-cycle development was completely integrated in his mind. Today, with the increasing of the products complexity, the whole life-cycle development is divided into several steps. Each one involve several sub-divisions, where each professional, using his own skills and 
experience, add value to the product. To do that each professional, usually, knows nothing about the subsequent steps.

In order to achieve the best results, aiming to come up with the most competitive product of the market, in a short period of time, all the steps of the whole life-cycle development must be fully integrated (as in the craftsman mind). This means human and information integration.

In order to advise this integration it is necessary multifunctional teamwork and Information System to provide the adequate support. The results achieved in a real industrial case study, have shown the Feature Technology potential to model and link the information coming from different areas of the product life-cycle development

The main contributions of the authors described in this paper could be considered as the feature-based approach to the part modeling in order to create a concurrent engineering environment. It is really important once product information central information in those environments.

We would like to acknowledge the European Commission for the possibility to develop work together.

\section{REFERENCES}

Afsarmanesh, H.; Wiedijk, M.; Ferreira, A.C.; Moreira, N.P. (november, 1993) An Approach to the Design of a Distributed CIM Database for a Brazilian Aerospace Industry. Proceedings of the European-Community-Latin America Workshop on Computer Integrated Manufacturing 93. Monte de Caparica, Portugal.

Afsarmanesh, H.; Moreira, N.P.; Wiedijk, M.; Ferreira, A.C. (june, 1994) Design of a Distributed Database for a Concurrent Engineering Environment. Proceedings of the European-Community-Latin America Workshop on Computer Integrated Manufacturing 94. Florianópolis, Brazil.

Bedworth, D.; Henderson, M.R.; Wolfe, P.M. (1991) Computer-Integrated Design and Manufacturing. McGraw-Hill, ISBN 0-07-004204-7.

Camarinha, L.M.; Osório, A.L. (1994) An Integrated Plataform for Concurrent Engineering. III CIMIS.net Workshop. Florianópolis, Brazil.

Chen, C-S.; Swift, F.; Lee, S.; Ege, R.; Shen, Q. (1992) Development of a Feature-Based and Object-oriented Concurrent Engineering System. Proceedings of the International Conference on Object-Oriented Manufacturing-systems. University of Calgary, Alberta, Canada.

Hernandez, J.; Rodrigues, M.; Ferreira, A.; Zendron, P. (august, 1991) IAGE: A Feature Oriented CAPP System. GRUCON/UFSC. Internal Report.

Holanda, A.B. (1988) Pequeno Dicionário da Língua Portuguesa. São Paulo, Brazil.

Huthwaite, B. Scheneberger, D. (1994) Design for Competitiveness. Institute for Competitive Design. USA.

Ishii, K. (1993) "Modeling of Concurrent Engineering Design" in Concurrent Engineering: Automation, Tools, and Techniques. Edited by Andrew Kusiak. John Wiley \& Sons. Inc.

Jo, H.H.; Parsael, R.; Wong, J.P. (1991) Concurrent Engineering: The Manufacturing Philosophy for the 90's. Computers in Industrial Engineering. Vol. 21. Nos 1-4. 
Kusiak, A. and Wang, J. (1993) "Decomposition in Concurrent Design" in Concurrent Engineering: Automation, Tools, and Techniques. Edited by Andrew Kusiak. John Wiley \& Sons. Inc.

Lindenberg, L. (1993) Notes on Concurrent Engineering. Annals of the CIRP. Vol 42/1/1993.

Longman (1983) Dictionary of American English. Edited by Longman. New York, USA.

Moreira, N.P. and Ferreira, A.C. (november, 1991) Feature Technology in CIM: tools and application. Simpósio sobre CAE/CAD/CAM. Sobracon. Brazil (in Portuguese).

Moreira, N.P. and Ferreira, A.C. (july, 1992) Open environment aiming CIM: a basic proposal. Congresso Internacional de Computação Gráfica. Sobracon. Brazil (in Portuguese).

Moreira N.P. (1993) An Information Modeling Proposal to the Manufacturing Integration and Concurrent Engineering. Master Thesis. Universidade Federal de Santa Catarina (in Portuguese).

Moreira, N.P.; Cabral, P.H.; Oliva, S. (1994) An Approach to Concurrent Engineering Implementation in EMBRAER-EDE. Annals of SAE Brasil 94. São Paulo, Brazil.

Shah, J.; Rogers, M. (february, 1988a) Functional Requirements and Conceptual Design of the Feature-Based Modeling System. Computer-Aided Engineering Journal.

Shah, J.; Sreevalsan, P.; Rogers, M.; Billo, R.; Mathew, A. (november, 1988b) Current Status of Features Thechnology. CAM-I Report R-88-GM-04.1.

Shah, J. (june, 1991) Assessment of Feature Technology. Computer Aided Design. Vol 23. Nro 5.

Terpenny, J.P. and Deisenroth, M.P. (july, 1992) A Concurrent Engineering framework: three basic components. Flexible Automation and Information Management - FAIM.

Tonshoff, H.A.; Aurich, J.C.; Baum, T. (1994) Configurable feature-based CAD/CAPP System. Proccedings of IFIP international conference. France.

Yeo, S.H.; Wong, Y.S.; Rhaman, M. (1991) Integrated knowledge-based machining system for rotational parts. International Journal of Production Research. Vol 29. No 7. 